\title{
Model and Resilience Analysis for Handling Chain Systems in Container Ports
}

\author{
Bowei Xu $\left(\mathbb{D},{ }^{1}\right.$ Junjun Li $\left(\mathbb{D},{ }^{2}\right.$ Yongsheng Yang $\mathbb{D}{ }^{1}$ \\ Huafeng $\mathrm{Wu}^{2}$, and Octavian Postolache $\mathbb{C}^{3}$ \\ ${ }^{1}$ Institute of Logistics Science \& Engineering, Shanghai Maritime University, Shanghai 201306, China \\ ${ }^{2}$ Merchant Marine College, Shanghai Maritime University, Shanghai 201306, China \\ ${ }^{3}$ Instituto de Telecomunicacoes, ISCTE-IUL, Av. Das Forcas Armadas, Lisbon 1049-001, Portugal \\ Correspondence should be addressed to Junjun Li; jsliljj@163.com
}

Received 1 April 2019; Accepted 2 July 2019; Published 22 July 2019

Academic Editor: Marcin Mrugalski

Copyright (C) 2019 Bowei Xu et al. This is an open access article distributed under the Creative Commons Attribution License, which permits unrestricted use, distribution, and reproduction in any medium, provided the original work is properly cited.

Container ports are critical components of global port and shipping supply chain (PSSC) systems. Their handling operation resiliencies can affect their performance, along with those of the overall port and shipping supply chain. According to the characteristics of the container handling operations, this study establishes a modeling paradigm for quantifying the resilience of handling chain system (HCS) in container ports. Considering the nonnegative arrive rate and the container handling completion rate, with the upper limit in real container port environments, nonlinear links have been added into the model of the HCS. The resilience of the HCS was analyzed according to the different pole distributions of unsatisfied freight requirement transfer function. Simulation results show that the upper limit of the container handling completion rate has a significant impact on the resilience of the HCS. The contributions herein demonstrate a starting point in the development of a quantitative resilience decision making framework and mitigating the negative impacts for port authorities and other players in the PSSC.

\section{Introduction}

In the global supply chain era, container ports are becoming increasingly important for modern societies. As the essential point of intersection between shipping and traffic, container ports have evolved from the traditional functions of cargo handling and storage to becoming integral parts of global port and shipping supply chain (PSSC) (Wang and Cheng 2010) [1]. They play a significant role in Chinese and world economies, serving as the backbone to the import and export trade and supply chain networks. Their development not only is directly related to the promotion of the "One Belt and One Road Initiative" but is also related to the implementation of the national strategy "Yangtze River Economic Belt". China has become the world largest container gathering area (Wang et al., 2017) [2]. In 2017, there were seven Chinese ports among the top ten container ports in the world.

The container port and shipping supply chain is a service supply chain with the container port enterprise at its core and smart information technology as the means. It has a service network structure composed of upstream and downstream enterprises to add value through customs and services (Jiang et al., 2018) [3]. Under global economic integration, largesize container vessels, and liner company alliance, container ports are no longer considered as solitary nodes (Song and Panayides, 2007) [4]; its competitive position is increasingly dependent on handling operation resilience and synergies with the transport nodes within port and shipping supply chain networks. Correspondingly, handling operation of a container port should match and collaborate with its freight requirement for not only providing value-added services to port users (Pettit and Beresford, 2009; Woo et al., 2013) [5, 6], but also ensuring the port capacity and performance (Hou and Geerlings, 2016; Rødseth et al., 2018) [7, 8].

1.1. Literature Review. With respect to port and shipping supply chain, most of previous studies have focused on terminal operating company and customers (Tongzon et al., 
2009; Hou and Geerlings, 2016) [7, 9], conceptual discussions of resilience with several qualitative definitions ( $\mathrm{Ta}$ et al., 2009) [10], port supply chain integration strategies and its relationship with port performance (Woo et al., 2013) [6], and so on. Port resiliency is the ability to resume normal operations at pre-disruptive performance levels after a disruptive adverse event and maintain normal operations and performance over a long period of disruptive adverse change (Gharehgozli et al., 2017) [11]. Although there is no generally accepted definition of PSSC resilience, there is consensus among many researchers that resilience is the common characteristic of efficient PSSCs with expected delivery capacity of container ports. Such collaboration and coordination among the container port and its players will also facilitate the establishment of the resilient port, which in turn enables a PSSC more flexible and proactive to uncertain environments (Loh and Thai, 2016) [12]. Specifically to PSSC resilience, Loh and Thai (2016) [12] introduced a portrelated supply chain disruptions management model that incorporated the application of risk management, business continuity management, and quality management theories with the purpose of increasing port resilience such that supply chain continuity was enhanced. Gharehgozli et al. (2017) [11] proposed a conceptual framework for evaluating how ports currently strategized against potential risks and how they planned to ensure port resiliency. Zavitsas et al. (2018) [13] considered the impact of Emission Control Areas and established a link between environmental and network resilience performance for maritime supply chains using operational cost and SOx emissions cost metrics. Despite the important role of resilience in enhancing performance improvements for PSSCs, no studies have been identified to quantify the resilience of handling chain system (HCS) in container ports and examine the real impact of nonlinearities on operation resilience, such as control method, while including those important players in the PSSC. However, this is not an easy task as there are many dynamics at play. It is critical for the success of a PSSC to understand the uncertainties and their impact and propose the corresponding measurements to cope with them. Thus, there is a need for quantitative measurement instruments to appropriately evaluate the resilience of HCS in container ports.

System dynamics intervention has been promoted to identify how structure and decision policies generate system behavior and to implement structural and policy-oriented solutions (Saleh et al., 2010; Yang et al., 2019) [14, 15]. Numerous studies have made efforts to understand and define system dynamics in manufacturing supply chains. They have designed production and inventory control systems to improve transportation and production operations, as well as to increase service and financial performance of those systems (John et al., 1994) [16]. Gabbar (2008) [17] proposed a model-based control mechanism and intelligent control layer to control the operation of chained production enterprises. $\mathrm{Li}$ et al. (2016) [18] developed a fuzzy comprehensive evaluation model of feature operation chain selection to realize the selection of possible feature operation chains based on processing requirements. Virginia Spiegler and Mohamed Naim (2017) [19] utilized a nonlinear production and inventory control model to provide insight into the impact of system constraints and therefore facilitated a more effective system design. Almaktoom (2017) [20] introduced a method of quantifying the reliability of an inventory management system and developed a reliability-based robust design optimization model to optimally allocate and schedule time while considering uncertainty associated with inventory movement. Ma et al. (2018) [21] investigated the impact of lead-times of retailers and manufacture, forecasting precision, callback index, and marketing share on the bullwhip effect of both retailers and manufacture. In this sense, it is vastly accepted that production planning and control systems play a crucial role in improving overall performance (Almaktoom, 2017) [20]. Understanding how differently they impact on performance would enable managers to select between different control strategies in the resilience operation field. However, they are far from being widespread in the practice of PSSC. This underscores the need for further exploring the dynamics of these PSSC systems.

1.2. Motivation for Work. Container ports are mainly categorized as inland and sea container ports. Both inland and sea container ports have the similar handling operations. General model of main inland port operations proposed by Pant et al. (2014) [22] is also suitable for container ports. The landside and seaside operations of a container terminal are its main container handling operations. They are divided into five components, as illustrated in Figure 1: (i) delivery/receipt, including the arrival of exported containers and departure of imported containers, (ii) landside/seaside yard crane loading and unloading operations, defined as the temporary storage of containers at the yard, (iii) yard truck/AGV operations, defined as the horizontal transportation of containers between berth and yard, (iv) gantry crane loading and unloading operations, used to transfer container cargoes to and from port docks, and (v) container vessel shipment, or the departure of containers for exports and the arrival of containers for imports (Pant et al., 2014) [22]. These individual operations are interrelated to form a tightly connected container handling chain system (HCS).

The container port and shipping supply chain is a dynamic system with bullwhip effect that involves the constant flow of information, containers, services, and funds between different stages. Currently, the research of bullwhip effect mainly focuses on theoretical study of general model of manufacturing supply chain, while some service supply chain models with practical significance have not been explored yet. Each stage of the container port HCS performs different processes and interacts with other stages of the system. As propagated through the HCS in container ports, oscillations such as uneven container flow and large-size container vessels have been associated with serious handling pressure, increased operation costs, and poor service levels and therefore need to be properly understood and controlled. The dynamics of a container port product operation chain can significantly impact the performance of upstream and downstream operations. These dynamics are normally driven by the application of different handling control policies and 


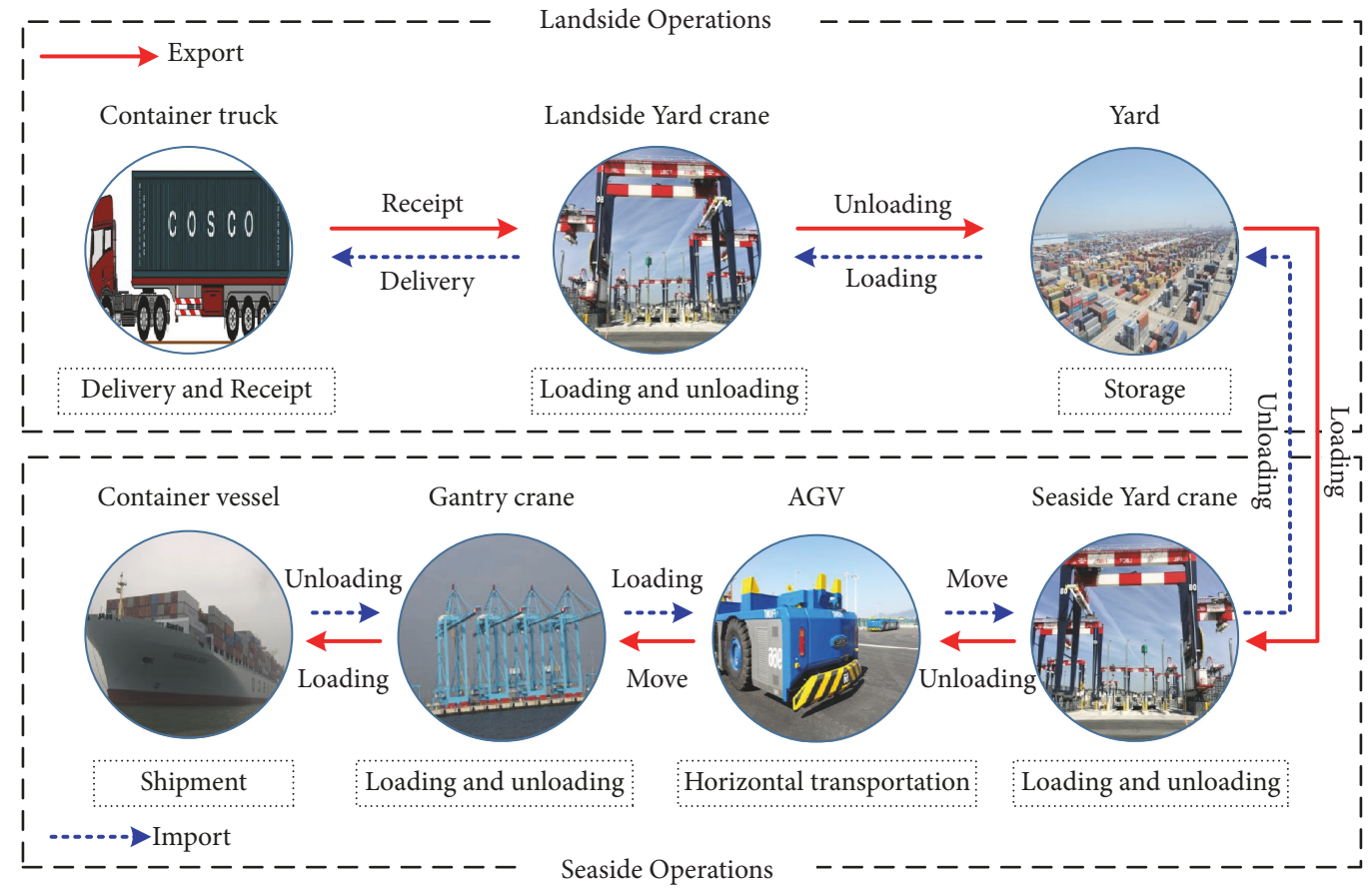

FIGURE 1: General model of container handling operations in automated container ports.

have the potential to cause discrepancies between freight requirements and handling operations.

In this regard, we have the intention of adapting the Automated Pipeline, Inventory, and Order Based Production Control System (APIOBPCS) (John et al., 1994) [16] in manufacturing supply chains to PSSC for improving the operation performance of container ports. This study first identifies characteristics of the handling operations by establishing a modeling paradigm for quantifying the resilience of HCS in container ports. In the next step, this study considers both the nonnegative arrive rate of container cargo and the container handling capacity with the upper limit explicitly. Nonlinear links have been added into the model of the HCS. In addition, for the first time, this study has conducted complete analysis of the HCS resilience under varying pole distributions of unsatisfied freight requirement (UFR) transfer function more precisely. Using the proposed model, we consistently develop final values of unsatisfied freight requirement $(u f r(t))$ and container handling completion rate (comrate $(t))$ within the steady state condition. Finally, simulation results show that the upper limit of the container handling completion rate has a significant impact on the resilience of HCS. The contributions herein will not only ensure decision making by port manager to protect ports and make them more resilient but also promote socially efficient handling chains.

\section{Models of Container Port Handling Chain System}

2.1. Linear Model. The container port and shipping supply chain is a service supply chain system as a network of suppliers, service providers, consumers, and other supporting units that performs the function of the delivery of containers to customers (Wang et al., 2015) [23]. Container port and shipping services are important in service supply chain, as they significantly influence freight requirement (FR). Obviously, proper freight requirement management and related operational measures are crucial to the success of container port and shipping supply chain. A novel model for HCS in container ports shown in Figure 2 is adapted from APIOBPCS model in manufacturing supply chain (John et al., 1994) [16], which extended the original Inventory and Order-based Production Control System (IOBPCS) archetype (Towill, 1982) [24] by incorporating an automatic work-in-progress (WIP) feedback loop. The APIOBPCS model (John et al., 1994) [16], a base framework for a production planning and control system, can be expressed as follows: the order placed is based on the forecast of customer demand plus a fraction ( $1 / T_{\mathrm{i}}$, proportional controller for inventory adjustment) of the discrepancy between actual and desired inventory levels plus a fraction ( $1 / T_{\mathrm{w}}$, proportional controller for WIP adjustment) of the discrepancy between actual WIP and target WIP levels (Zhou et al., 2017) [25]. One of the main objectives when designing an APIOBPCS is to obtain a desirable inventory level avoiding severe order and inventory variability in the face of exterior disturbances (Almaktoom, 2017) [20].

The Laplace transform is utilized in Figure 2 for our control engineering analysis coupled with simulation modeling. $s$ is a complex frequency in Laplace transform. Parameters and segments are detailed in Table 1. In the following work, uppercase and lowercase words, such as $F R$ and $f r$, are used in the frequency and time domains, respectively. The input and output of this model are freight requirement (FR) and unsatisfied freight requirement (UFR), respectively. The 


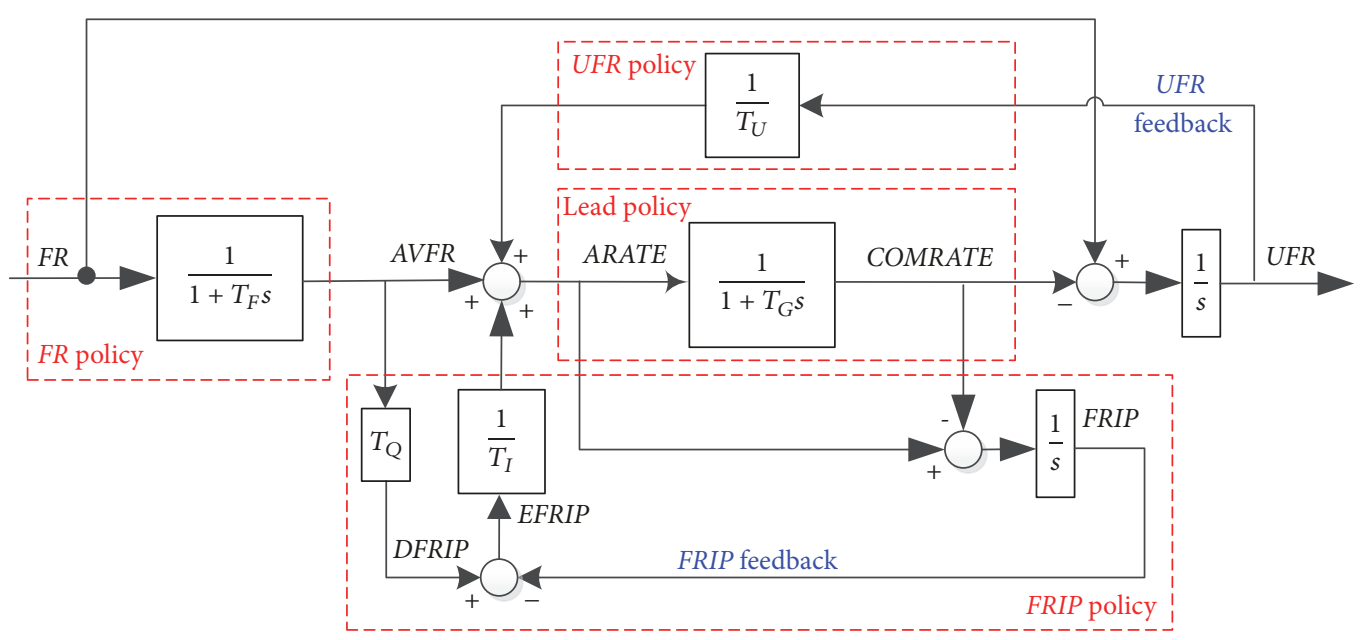

FIGURE 2: Linear model of handling chain system in container ports.

TABLE 1: Parameters and segments in linear model.

\begin{tabular}{lccccc}
\hline FR & Freight requirement & AVFR & Average FR & ARATE & Arrive rate \\
\hline COMRATE & $\begin{array}{c}\text { Container handling } \\
\text { completion rate }\end{array}$ & UFR & Unsatisfied FR & FR in process \\
\hline DFRIP & $\begin{array}{c}\text { Desired FRIP } \\
T_{F}\end{array}$ & EFRIP & Error in FRIP & $\begin{array}{c}T_{U} \\
\text { Adjustment time of } \\
\text { UFR }\end{array}$ \\
\hline$T_{I}$ & $\begin{array}{c}\text { Adjustment time of } \\
\text { forecast }\end{array}$ & $\frac{1}{1+T_{F} s}$ & $\begin{array}{c}\text { Freight requirement } \\
\text { policy }\end{array}$ & $\begin{array}{c}T_{Q} \\
\text { handling operations }\end{array}$ & $\begin{array}{c}\text { Expected lead-time of } \\
\text { handling operations }\end{array}$ \\
\hline
\end{tabular}

container arrive rate $(A R A T E)$ takes the integrals of average freight requirement $(A V F R)$, error in freight requirement in process (EFRIP), and unsatisfied freight requirements (UFR) into account. $1 /\left(1+T_{F} s\right)$ and $1 /\left(1+T_{G} s\right)$ are employed as the freight requirement policy and the lead policy of handling operation in container port, respectively. Container handling completion rate (COMRATE) can be taken as the input of the next. $T_{U}$ denotes adjustment time of $U F R, T_{F}$ denotes time constant of $F R$ forecast, $T_{G}$ denotes real leadtime of handling operations, $T_{Q}$ denotes expected lead-time of handling operations, and $T_{I}$ denotes adjustment time of EFRIP. Controllable decision variables, $T_{U}, T_{F}, T_{G}, T_{Q}$, and $T_{I}$, are all positive real numbers.

As shown in Figure 2, the HCS model in container ports can be expressed as follows: the container arrive rate (ARATE) placed is based on the forecast of freight requirement $(F R)$ plus a fraction $\left(1 / T_{U}\right.$, the proportional controller for unsatisfied freight requirement adjustment) of the unsatisfied freight requirement $(U F R)$ plus a fraction $\left(1 / T_{I}\right.$, the proportional controller for $F R$ in process adjustment) of the discrepancy between actual FR in process (FRIP), and desired FRIP levels. The differences between APIOBPCS and HCS in container ports are not only with or without a desired inventory level, but also the meaning of each terminology in HCS has been updated according to the characteristics of container port and shipping supply chain, such as parameter $T_{F}$ related to handling operations planning in container terminal, parameters $T_{G}$, and $T_{Q}$ related to the concentrated receipt of export containers ahead of container vessel arrival, parameter $T_{I}$ related to the fast loading and unloading of container vessels, and parameter $T_{U}$ related to the detention time of containers in port yard. Each parameter in the HCS model of container ports originates from handling operation practice. They undoubtedly have important practical guiding significance for container port operation management. The main purpose of HCS in container ports is to obtain an unsatisfied freight requirement (UFR) as small as possible or even equal to zero and maintain optimal handling operation resilience.

As described in Figure 2, it is possible to determine the UFR transfer function, the COMRATE transfer function, and the ARATE transfer function in relation to the input $F R$ :

$$
\begin{aligned}
& \frac{U F R}{F R} \\
& =\frac{\left(T_{G}+T_{I}+T_{I} T_{G} s\right)\left(1+T_{F} s\right)-T_{Q}-T_{I}}{T_{I} T_{G} T_{F}\left[1 / T_{U} T_{G}+\left(1 / T_{I}+1 / T_{G}\right) s+s^{2}\right]\left(s+1 / T_{F}\right)} \\
& \frac{\text { COMRATE }}{F R} \\
& =\frac{T_{I}+\left(T_{I} T_{F}-T_{U} T_{Q}-T_{U} T_{I}\right) s}{T_{U} T_{I} T_{G} T_{F}\left[1 / T_{U} T_{G}+\left(1 / T_{I}+1 / T_{G}\right) s+s^{2}\right]\left(s+1 / T_{F}\right)}
\end{aligned}
$$




$$
\begin{aligned}
& \frac{\text { ARATE }}{F R} \\
& =\frac{\left(1+T_{G} s\right)\left[T_{I}+\left(T_{I} T_{F}-T_{U} T_{Q}-T_{U} T_{I}\right) s\right]}{T_{U} T_{I} T_{G} T_{F}\left[1 / T_{U} T_{G}+\left(1 / T_{I}+1 / T_{G}\right) s+s^{2}\right]\left(s+1 / T_{F}\right)}
\end{aligned}
$$

(1) Steady State Condition. One of the poles is easily identified $\left(p_{0}=-1 / T_{F}\right)$. The other two poles are set as $p_{1}$ and $p_{2}$. Then,

$$
\begin{aligned}
p_{1}+p_{2} & =\frac{1}{T_{I}}+\frac{1}{T_{G}}, \\
p_{1} p_{2} & =\frac{1}{\left(T_{U} T_{G}\right)} .
\end{aligned}
$$

Then it can be seen that the steady state condition is $1 / T_{I}+$ $1 / T_{G}>0,1 /\left(T_{U} T_{G}\right)>0$, and $1 / T_{F}>0$. Because $T_{U}, T_{F}, T_{G}$, $T_{Q}$, and $T_{I}$ are all positive real numbers, this system is stable.

(2) Final Value of $u f r(t)$ and comrate $(t)$. In deriving transfer functions in complex frequency domain, we exploit the classic step input as it helps to develop insights into dynamic behavior. We use the step response to assess the system's ability to cope with oscillations in the linear HCS. The step response is powerful, as from this simple $F R$ input, the size, and quantity of the subsequent $u f r(\infty)$, comrate $(\infty)$ and $\operatorname{arate}(\infty)$ can be readily determined, providing a rich understanding of the dynamics of the linear HCS. If $F R$ is a unit step signal, $u f r(\infty)$, comrate $(\infty)$ and arate $(\infty)$ can be obtained by final value theorem:

$$
\begin{aligned}
& \text { ufr }(\infty)=\lim _{s \rightarrow 0} s \cdot \operatorname{UFR}(s) \\
& =\lim _{s \rightarrow 0} \frac{\left(T_{G}+T_{I}+T_{I} T_{G} s\right)\left(1+T_{F} s\right)-T_{Q}-T_{I}}{T_{G} T_{F}\left[1 / T_{U} T_{G}+\left(1 / T_{I}+1 / T_{G}\right) s+s^{2}\right]\left(s+1 / T_{F}\right)} \\
& =\frac{T_{U}\left(T_{G}-T_{Q}\right)}{T_{I}} \\
& \text { comrate }(\infty)=\lim _{s \rightarrow 0} s \cdot \operatorname{COMRATE}(s) \\
& =\lim _{s \rightarrow 0} \frac{T_{I}+\left(T_{I} T_{F}-T_{U} T_{Q}-T_{U} T_{G} T_{F}\left[1 / T_{U} T_{G}+\left(1 / T_{I}+1 / T_{G}\right) s+s^{2}\right]\left(s+1 / T_{F}\right)\right.}{T_{I} / T_{U}}=1 \\
& \text { arate }(\infty)=\lim _{s \rightarrow 0} s \cdot A R A T E(s) \\
& =\lim _{s \rightarrow 0} \frac{\left(1+T_{G} s\right)\left[T_{I}+\left(T_{I} T_{F}-T_{U} T_{Q}-T_{U} T_{I}\right) s\right]}{T_{I} T_{G} T_{F}\left[1 / T_{U} T_{G}+\left(1 / T_{I}+1 / T_{G}\right) s+s^{2}\right]\left(s+1 / T_{F}\right)} \\
& =\frac{T_{I} T_{F}}{T_{I} T_{F}}=1
\end{aligned}
$$

It can be seen that $u f r(\infty)$ depends on $T_{U}, T_{I}$, and the difference between $T_{G}$ and $T_{Q} \cdot u f r(\infty)$ would be 0 only when $T_{G}=T_{Q}$. comrate $(t)$ and arate $(t)$ will approach 1 when $t \rightarrow \infty$. Therefore, when the HCS reaches its steady state, comrate $(t)$ and $f r(t)$ are balanced, and $u f r(t)$ no longer changes.
2.2. Nonlinear Model. In real environments of container ports, the value of ARATE cannot be negative, although mathematically it holds. The upper value of COMRATE is limited; however, the linear model in Figure 2 cannot guarantee these two nonlinear natures. To reflect them, a nonlinear HCS model consisting of two nonlinear segments is given in Figure 3. ARATE' is the theoretical arrive rate which equals to $\operatorname{avfr}(t)+u f r(t) / T_{U}+e f r i p(t) / T_{I}$; COMRATE' is the theoretical container handling completion rate, which is only calculated by arate $(t)$ and the handling operation policy $1 /\left(1+T_{G} s\right)$; COMRATE $E_{m}$ is the upper limit of COMRATE. COMRATE $E_{m}$ should not be less than $f r(t)$ over time; otherwise $u f r(t)$ will continuously increase.

If COMRATE $E_{m}$ is equal to $f r(t)$ or, slightly larger than $f r(t)$, the actual container handling completion rate would not process the accumulated freight requirement timely. Then $u f r(\infty)$ may be larger than $T_{U}\left(T_{G}-T_{Q}\right) / T_{I}$. If $u f r(t)$ is too large, it would congest the HCS.

\section{Resilience for Handling Chain System}

To understand the resilience for HCS in container ports, we use the integral of time multiplied by the absolute error (ITAE) as a benchmark. ITAE emphasizes long-duration errors. It is recommended for the analyses of systems which require a fast settling time. The minimum value of ITAE corresponds to the best response and recovery with the lowest deviation from the target, or readiness (Virginia et al., 2012) [26]. The ITAE is given by ITAE $=\int_{0}^{+\infty} t \cdot|e(t)| d t=$ $\lim _{\delta t \rightarrow 0} \sum_{t=0}^{\infty} t|e(t)| \delta t$, where $e(t)=u f r(t)-u f r(\infty)$. To facilitate uniform analysis, $u f r(\infty)=T_{U}\left(T_{G}-T_{Q}\right) / T_{I}$, which is consistent with (5).

In linear HCS, $u f r(t)$ can be calculated in the following four cases below, where $A, B$, and $C$ are coefficients related to the system poles and $D$ is the coefficient of the step input pole $(s=0)$.

Case 1 (distinct poles: real and/or complex, $p_{1} \neq p_{2} \neq p_{0}$ ). (a) $\Delta_{1}>0\left(\Delta_{1}=T_{U}\left(T_{G}+T_{I}\right)^{2}-4 T_{I}^{2} T_{G}\right)$

$$
u f r(t)=A e^{p_{0} t}+B e^{p_{1} t}+C e^{p_{2} t}+D
$$

(b) $\Delta_{1}<0$

$$
\begin{aligned}
u f r(t)= & A e^{p_{0} t}+B e^{\sigma_{1} t}\left(\cos \omega_{1} t-j \sin \omega_{1} t\right) \\
& +C e^{\sigma_{2} t}\left(\cos \omega_{2} t-j \sin \omega_{2} t\right)+D
\end{aligned}
$$

In Case 1 (a) and (b), the coefficient values of $A, B$, and $C$ are

$$
\begin{aligned}
& A=\frac{T_{I}+T_{G}-T_{G} T_{I} D p_{2} p_{1}}{T_{G} T_{I}\left(p_{1}-p_{0}\right)\left(p_{2}-p_{0}\right)}, \\
& B=\frac{T_{I} T_{F}+T_{G} T_{F}+T_{G} T_{I}+T_{G} T_{I} T_{F}\left(p_{1}-D p_{2} p_{0}\right)}{T_{G} T_{I} T_{F}\left(p_{1}-p_{2}\right)\left(p_{1}-p_{0}\right)}, \\
& C=\frac{T_{G} T_{I}+T_{G} T_{F}+T_{I} T_{F}+T_{G} T_{I} T_{F}\left(p_{2}-D p_{0} p_{1}\right)}{T_{G} T_{I} T_{F}\left(p_{2}-p_{0}\right)\left(p_{2}-p_{1}\right)} .
\end{aligned}
$$




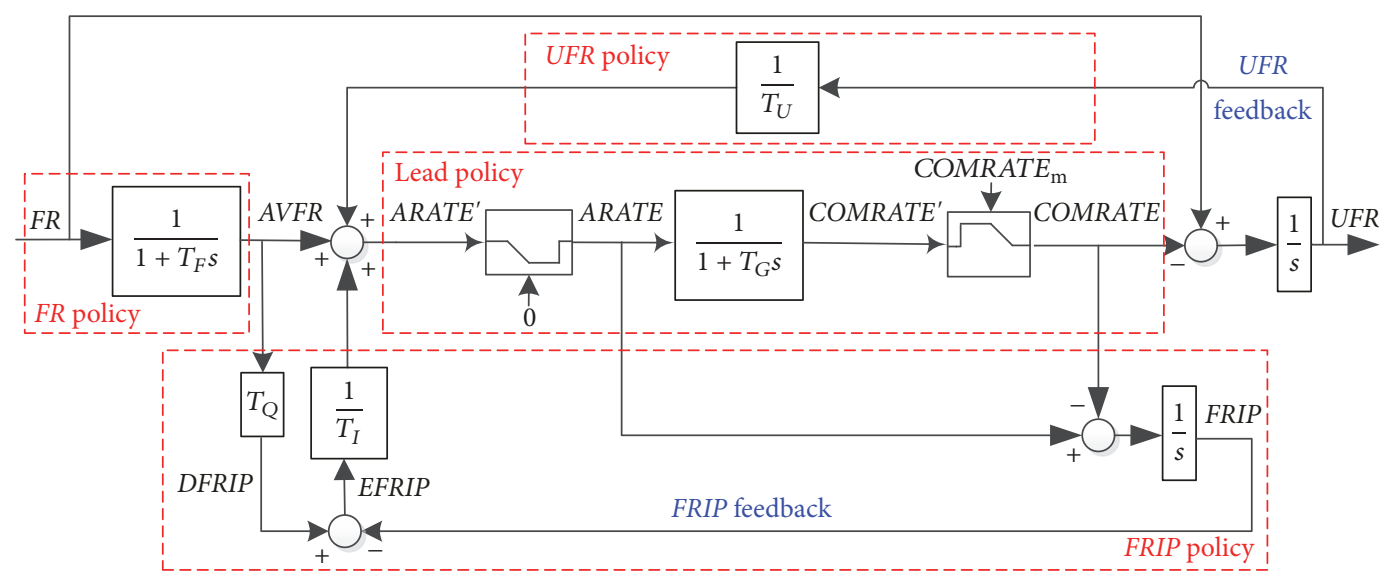

FIGURE 3: Nonlinear model of handling chain system in container ports.

Case 2 (two repeated poles: $p_{1}=p_{0}$ or $p_{2}=p_{0}$ ). (a) $p_{1} \neq p_{2}$, $p_{1}=p_{0}$

$$
u f r(t)=A e^{p_{0} t}+B t e^{p_{0} t}+C e^{p_{2} t}+D
$$

where

$$
\begin{aligned}
& A \\
& =-\frac{T_{G} T_{I}+T_{G} T_{F}+T_{I} T_{F}+T_{G} T_{I} T_{F}\left[p_{2}+D p_{2}\left(p_{2}-2 p_{0}\right)\right]}{T_{G} T_{I} T_{F}\left(p_{0}-p_{2}\right)^{2}}, \\
& B=\frac{T_{G}+T_{I}-T_{G} T_{I} D p_{0} p_{2}}{T_{G} T_{I}\left(p_{0}-p_{2}\right)}, \\
& C=\frac{T_{G} T_{I}+T_{G} T_{F}+T_{I} T_{F}+T_{G} T_{I} T_{F}\left(p_{2}-D p_{0}^{2}\right)}{T_{G} T_{I} T_{F}\left(p_{0}-p_{2}\right)^{2}}
\end{aligned}
$$$$
\text { (b) } p_{1} \neq p_{2}, p_{2}=p_{0}
$$$$
u f r(t)=A e^{p_{0} t}+B t e^{p_{0} t}+C e^{p_{1} t}+D
$$

where

$$
\begin{aligned}
& A \\
& =-\frac{T_{G} T_{I}+T_{G} T_{F}+T_{I} T_{F}+T_{G} T_{I} T_{F}\left[p_{1}+D p_{1}\left(p_{1}-2 p_{0}\right)\right]}{T_{G} T_{I} T_{F}\left(p_{0}-p_{1}\right)^{2}}, \\
& B=\frac{T_{G}+T_{I}-T_{G} T_{I} D p_{0} p_{1}}{T_{G} T_{I}\left(p_{0}-p_{1}\right)} \\
& C=\frac{T_{G} T_{I}+T_{G} T_{F}+T_{I} T_{F}+T_{G} T_{I} T_{F}\left(p_{1}-D p_{0}^{2}\right)}{T_{G} T_{I} T_{F}\left(p_{0}-p_{1}\right)^{2}}
\end{aligned}
$$

Case 3 (two repeated poles: $p_{1}=p_{2} \neq p_{0}$ ).

$$
u f r(t)=A e^{p_{1} t}+B t e^{p_{1} t}+C e^{p_{0} t}+D
$$

where

$$
\begin{aligned}
& A=-\frac{T_{G}+T_{I}+T_{G} T_{I} D p_{0}\left(p_{0}-2 p_{1}\right)}{T_{G} T_{I}\left(p_{1}-p_{0}\right)^{2}}, \\
& B=\frac{T_{G} T_{I}+T_{G} T_{F}+T_{I} T_{F}+T_{G} T_{I} T_{F}\left(p_{1}-D p_{0} p_{1}\right)}{T_{G} T_{I} T_{F}\left(p_{1}-p_{0}\right)}, \\
& C=\frac{T_{G}+T_{I}-T_{G} T_{I} D p_{1}^{2}}{T_{G} T_{I}\left(p_{1}-p_{0}\right)^{2}}
\end{aligned}
$$

Case 4 (three repeated poles: $p_{1}=p_{2}=p_{0}$ ).

$$
u f r(t)=A e^{p_{0} t}+B t e^{p_{0} t}+0.5 C t^{2} e^{p_{0} t}+D
$$

where

$$
\begin{aligned}
& A=-D, \\
& B=1+D p_{0}, \\
& C=\frac{1}{T_{G}}+\frac{1}{T_{I}}-D p_{0}^{2}
\end{aligned}
$$
1 (b)

In all cases, $D=T_{U}\left(T_{G}-T_{Q}\right) / T_{I}$. In all cases except Case

$$
\begin{aligned}
& p_{1}=\frac{-\left(T_{G}+T_{I}\right) \sqrt{T_{U}}+\sqrt{\Delta_{1}}}{2 T_{I} T_{G} \sqrt{T_{U}}}, \\
& p_{2}=\frac{-\left(T_{G}+T_{I}\right) \sqrt{T_{U}}-\sqrt{\Delta_{1}}}{2 T_{I} T_{G} \sqrt{T_{U}}} .
\end{aligned}
$$

In Case 1 (b),

$$
\begin{aligned}
& p_{1}=\sigma_{1}+j \omega_{1}, \\
& p_{2}=\sigma_{2}+j \omega_{2}, \\
& \sigma_{1}=\sigma_{2}=\frac{-\left(T_{G}+T_{I}\right)}{2 T_{I} T_{G}},
\end{aligned}
$$

$$
\omega_{1,2}=\frac{ \pm \sqrt{-\Delta_{1}}}{2 T_{I} T_{G} \sqrt{T_{U}}} .
$$




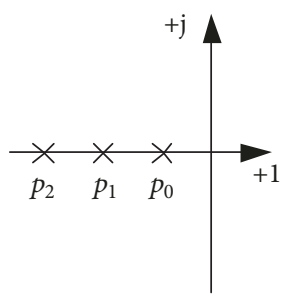

Case 1(a)

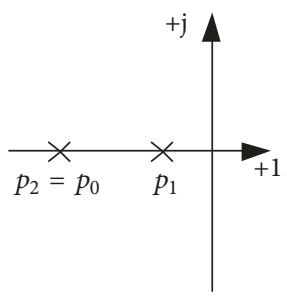

Case 2(b)

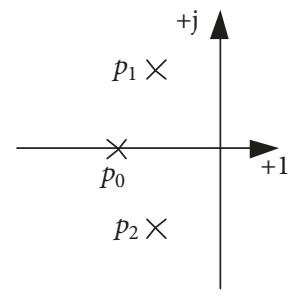

Case 1(b)

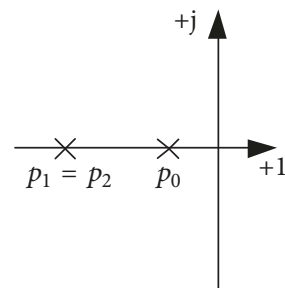

Case 3

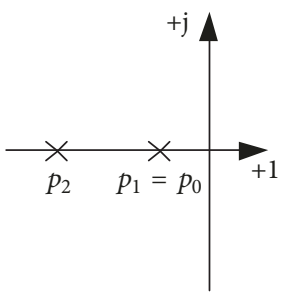

Case 2(a)

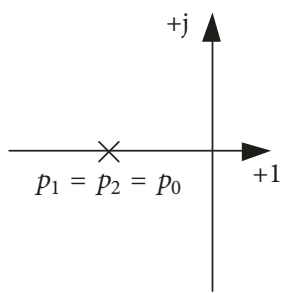

Case 4

FIGURE 4: Pole distributions of UFR transfer function.

The pole distributions of $U F R$ transfer function are shown in Figure 4:

It can be seen that $u f r(t)$ approaches $D$ in Cases 1 through 4. This is consistent with (5) in which $u f r(\infty)$ is equal to $D$.

In nonlinear HCS, if arate' $(t)<0$, or comrate' $(t)>C O M-$ $R A T E m, u f r(t)$ would be different from that in a linear HCS. Specifically, if comrate' $(t)>$ COMRATEm, $u f r(t)$ would increase because the actual container handling completion rate cannot process the freight requirement in time and $u f r(\infty)$ may be larger than D. ITAE would be different from that of linear HCS. If $u f r(\infty)>D$, ITAE would increase indefinitely.

\section{Resilience Analysis of HCS in Container Ports}

The quantitative resilience framework for HCS developed in this work is deployed with an illustrative example of a container port in China. Its HCS serves an important role in container flows around the world, and its resilience is vital to the larger multimodal transportation system and the PSSC. It has four container docks. Under normal operations, its annual container throughput would be around 4 million TEU. $T_{Q}$ would be between 0 and 3 days, while $T_{I}$ would be between 0 and 1 day. For the simulation models and resilience analysis, it is assumed that $T_{Q}=1.5$ days and $T_{I}=0.5$ days. $T_{G}$ is 1 day. $T_{F}$ is between 2 and 30 days, while $T_{U}$ is between 0 and 10 days. Based on the modeling concepts developed in the previous sections, resiliencies of two different HCSs are studied separately: (i) linear HCS and (ii) nonlinear HCS. Simulation code was written in MATLAB. If any of the HCS were to oscillate and become inoperable, it might stop the flow of containers handled by that dock and result in port congestions.
4.1. Resilience of Linear HCS. Linear HCSs are without limits for ARATE and COMRATE. Based on the above data, ITAE of linear HCS is calculated according to Section 3. The results of ITAE are calculated and plotted when $T_{F} \in$ [2 days, 30 days] and $T_{U} \in$ (0 day, 10 days]. 3D mesh and contour maps of ITAE are shown in Figures 5(a) and 5(b), respectively. In Figure 5, it can be seen that ITAE increases gradually with increases in $T_{F}$ and $T_{U}$ in most cases. But this change is not completely linear. When $T_{F}$ and $T_{U}$ approach 2 days and 10 days respectively, ITAE will gradually increase within a certain range. We are concerned about the values of $T_{F}$ and $T_{U}$ when ITAE reaches its minimum value. However, they are not easily found in Figure 5. For this reason, 3D mesh and contour maps of 1/ITAE are plotted in Figures 6(a) and 6(b), respectively. From Figure $6,1 /$ ITAE reaches its maximum value when $T_{F}=2$ days and $T_{U} \longrightarrow 0$ day $\left(T_{U} \neq 0\right)$. The minimum of ITAE is approximately equal to 5.2812. This implies that carefully setting the parameters $T_{F}$ and $T_{U}$ may improve dynamic performance of the linear HCS. In addition, it suggests that the closer the collaboration of port authorities and other players in PSSC is, the better the resilience of linear HCS is.

4.2. Resilience of Nonlinear HCS. Nonlinear HCS focuses on the limits for ARATE and COMRATE. How the ARATE and COMRATE influence the nonlinear HCS dynamics is to be examined. In nonlinear HCS, the smaller COMRATE $E_{m}$ is, the more likely it is that COMRATE' $(t)>C_{C O M R A T E}$, and the difference between $u f r(t)$ in nonlinear and linear HCSs is larger. Correspondingly, the difference between ITAE of nonlinear and linear HCSs is greater. In order to facilitate the obvious distinction, COMRATE $E_{m}=1.05$ here. When $T_{F} \in$ [2 days, 30 days] and $T_{U} \in$ (0 day, 10 days], 3D mesh and contour maps of ITAE are given in Figures 7(a) and 7(b), 


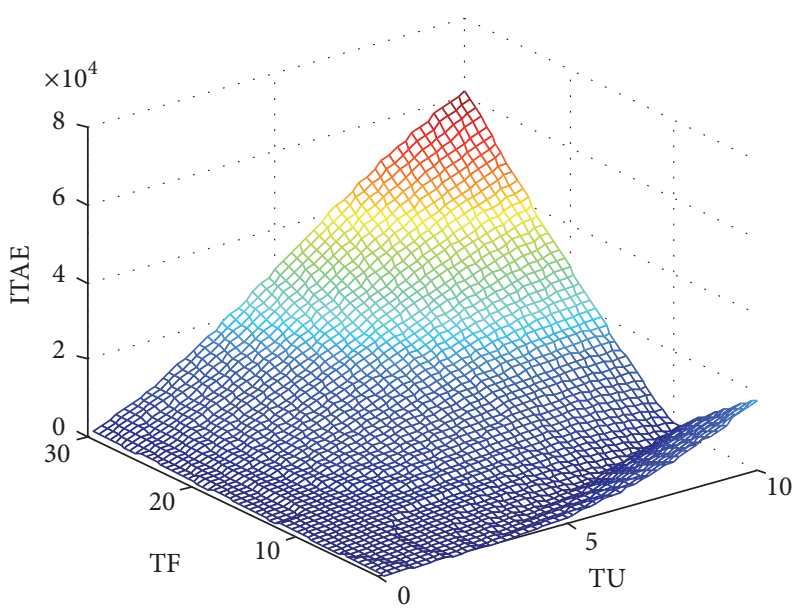

(a) 3D mesh map

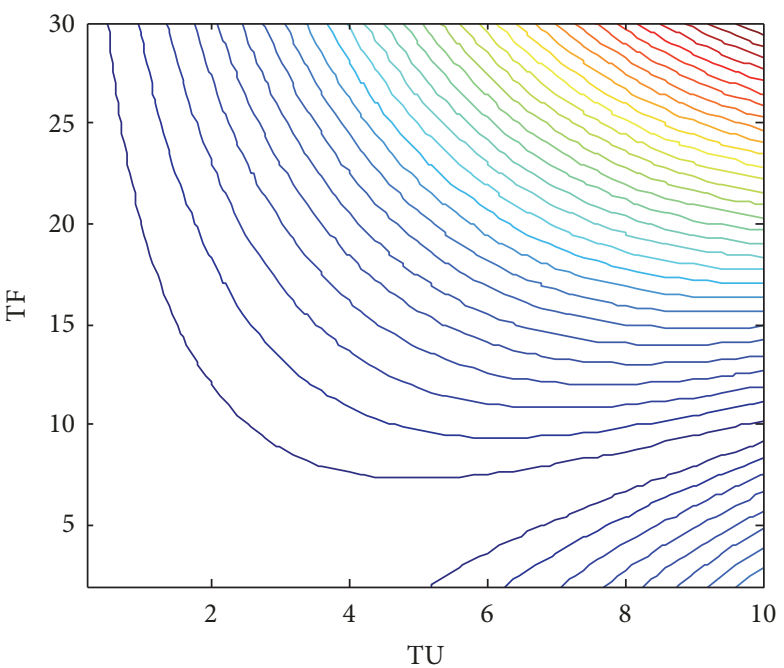

(b) Contour map

FIGURE 5: ITAE of linear handling chain system.

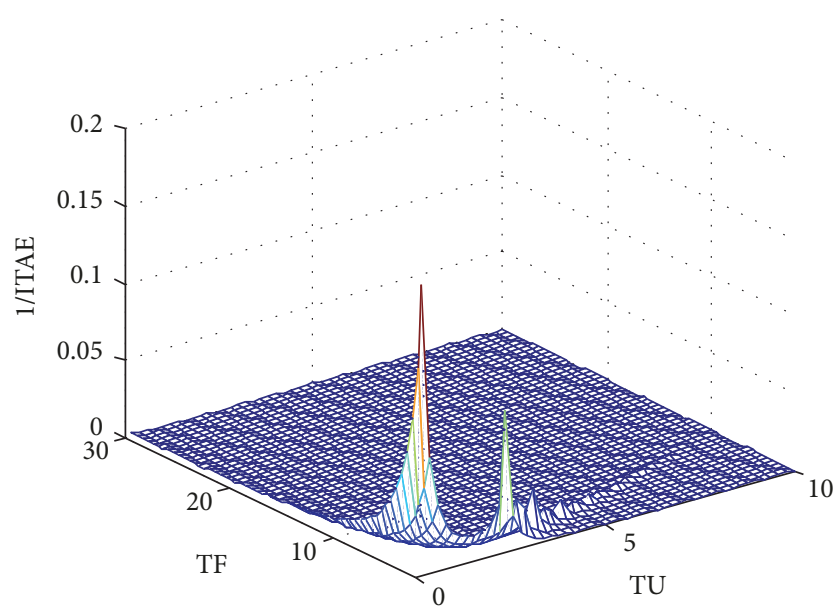

(a) 3D mesh map

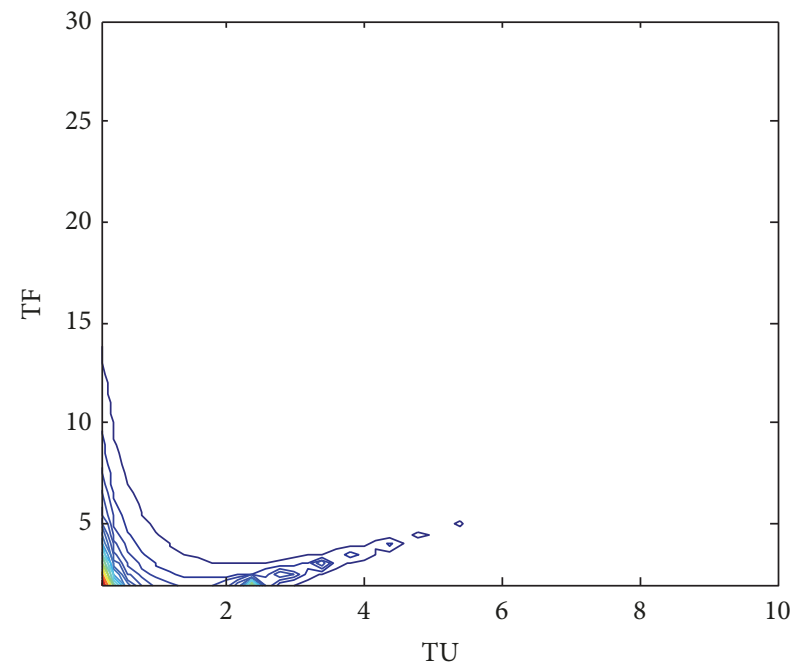

(b) Contour map

FIGURE 6: 1/ ITAE of linear handling chain system.

respectively. 3D mesh and contour maps of 1/ITAE are given in Figures 8(a) and 8(b), respectively. In Figure 8(a), some areas in which $u f r(\infty)>D$ and ITAE is infinite are not plotted. These areas are the light blue shaded regions in Figure $8(\mathrm{~b})$. From Figure 8, ITAE reaches its minimum value $(1 / I T A E \approx 0.092$ and $I T A E \approx 10.82)$ when $T_{F}=2$ days, $T_{U}=2.4$ days. From a comparison between Figures 5 and 7, ITAE (approximately 66.60\%) is infinity more than half of the entire area. It reveals that the impact of $C O M R A T E_{m}$ on container port performance is obvious. Considering these results can be determined that if COMRATE $E_{m}$ are just applied to the nonlinear HCS, modifying the setting of parameter $T_{U}$ will improve the resilience of the nonlinear HCS.

In Figure 6, there are two regions in which 1/ITAE gradually increases and reaches the peaks of these regions.
One region is close to the point of $T_{U}=0$ day and $T_{F}=2$ days, and the other region is close to the point of $T_{U}=2.4$ days and $T_{F}=2$ days. $1 /$ ITAE gradually reaches its maximum when approaching the point of $T_{U}=0$ day and $T_{F}=2$ days. This is most likely due to the fact that they are dependent processes. The faster the unsatisfied freight requirement is delivered, the sooner the linear HCS will recover to normal operation. Hence, reasonably setting the parameters $T_{F}$ and $T_{U}$ can solve port congestion problems, but it is important to take into account that each modification will affect the resilience of linear HCS.

In Figure 8, 1/ITAE becomes very small in the region close to the point of $T_{\mathrm{U}}=0$ day and $T_{\mathrm{F}}=2$ days. From Figure $8(\mathrm{~b})$, ITAE becomes infinite in this region. The new maximum of $1 /$ ITAE is in the point of $T_{\mathrm{U}}=2.4$ days and $T_{\mathrm{F}}=2$ days. The 


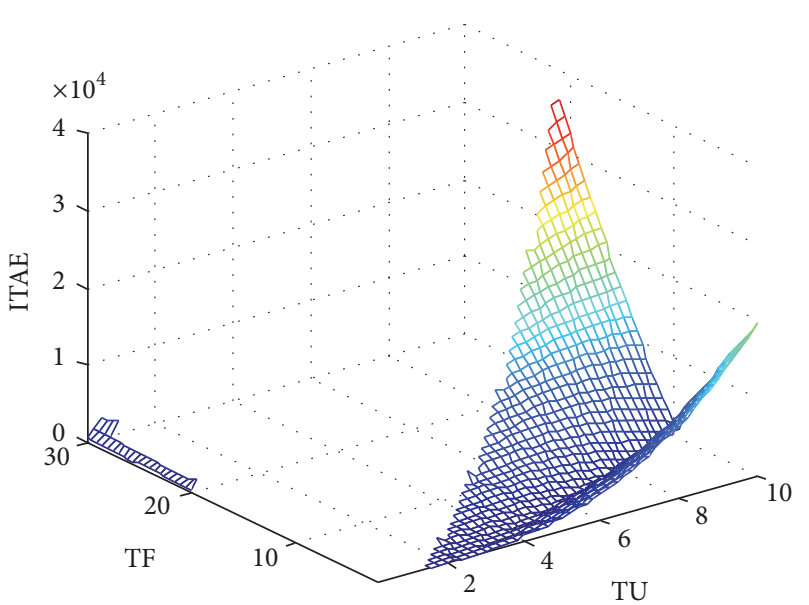

(a) 3D mesh map

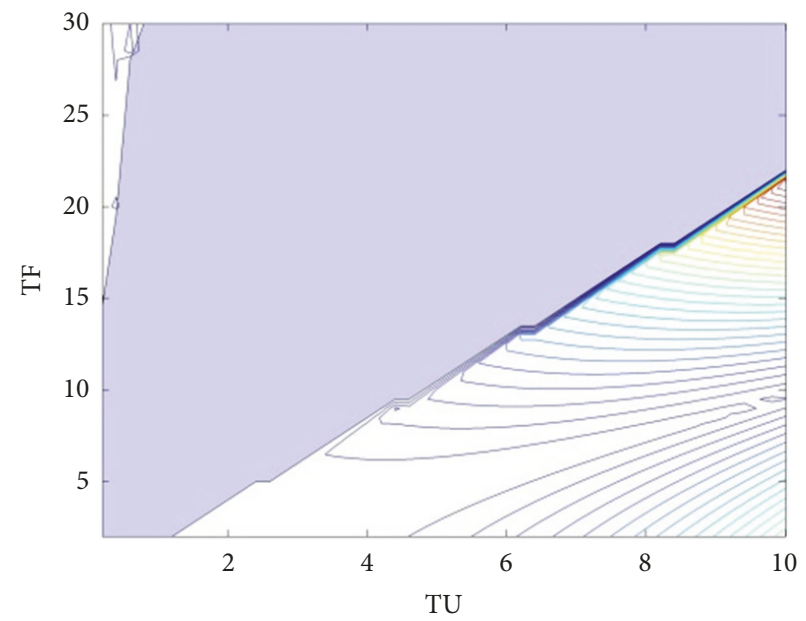

(b) Contour map

FIGURE 7: ITAE of nonlinear handling chain system.

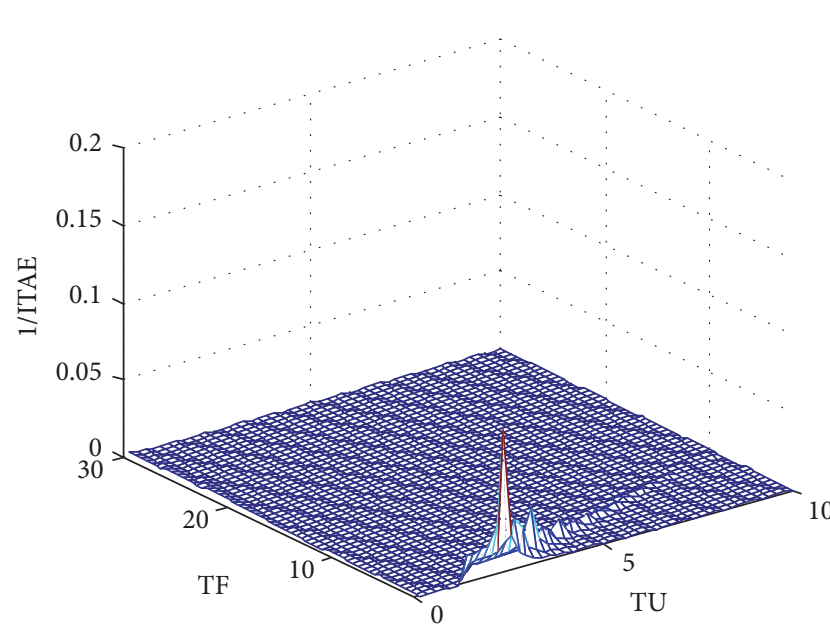

(a) 3D mesh map

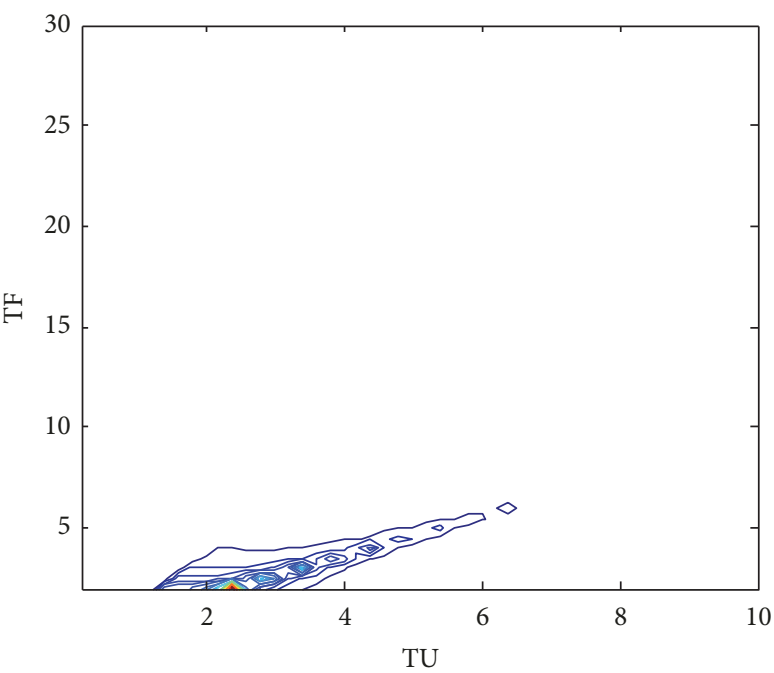

(b) Contour map

FIGURE 8: 1/ITAE of nonlinear handling chain system.

results of the two HCSs discussed above show the usefulness of the resilience measurement is highlighted in the analysis. These can be used for the PSSC's decisions.

4.3. COMRATE ${ }_{m}$ 's Influence on Nonlinear HCS. In order to examine how the COMRATE ${ }_{m}$ influences the nonlinear HCS dynamics, the point of $T_{F}=2$ days and $T_{U}=0.2$ day is taken as an example, and $u f r(t)$, arate $(t)$, and comrate $(t)$ are plotted in Figure 9 with different COMRATE ${ }_{m}\left(C O M R A T E_{m}\right.$ $=1.00,1.05,1.10,1.15$ and 1.20). date $\in[0$ day, 40 days]. In order to clearly distinguish these curves, the horizontal axis coordinates only take $0 \sim 15$ days in Figures 9(a) and 9(b). They eventually reach stable values. The stable value of $u f r(t)$ is different with different COMRATE $E_{m}$; the stable values of $\operatorname{arate}(t)$ and comrate $(t)$ are always 1 .
From Figure 9(a), the values of $u f r(t)$ with different COMRATE $_{m}$ are the same before it reaches its peak. After its peak, the values of $u f r(t)$ with different $C O M R A T E_{m}$ are quite different from one another. When COMRATE ${ }_{m}=1, u f r(t)$ maintains its peak value after reaching it. When COMRATE $=1.2, u f r(t)$ eventually is equal to $D(D=0.2)$, which is the same as that in the linear HCS. From Figure 9(b), in dates 2 through 8 , the enhanced $u f r(t)$ makes arate(t) higher when COMRATE $E_{m}$ is lower. From Figure 9(c), comrate $(t)$ is limited by COMRATE $m$ in dates $2 \sim 8$. This limitation results in the cumulative increase of $u f r(t)$. Due to the limited value of COMRATE, there are cases where dynamic behaviors of nonlinear HCS cause $f r(t)$ not to be handled timely, eventually resulting in the increased $u f r(t)$. Meanwhile, there would be change noted in $\operatorname{arate}(t)$. 


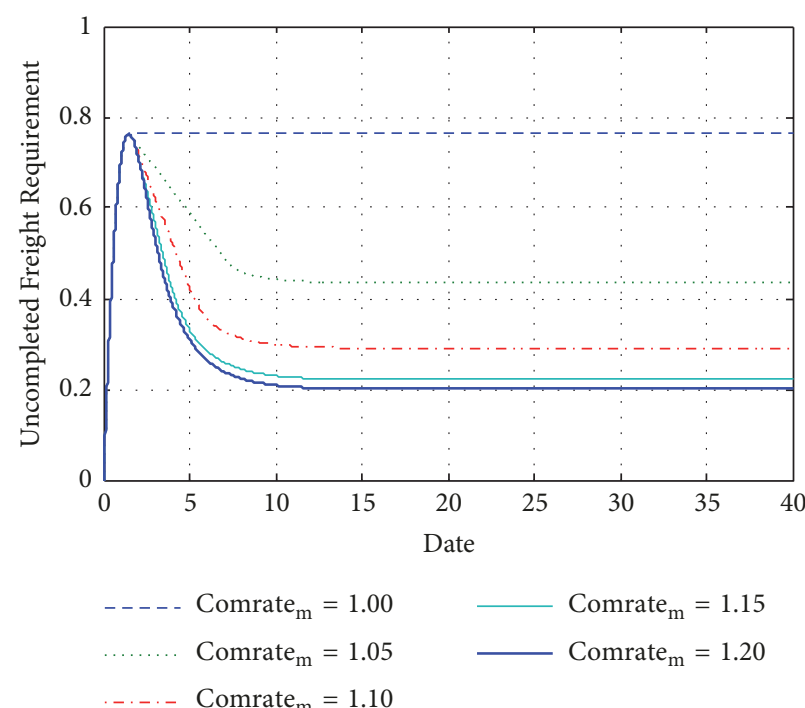

(a) $u f r(t)$

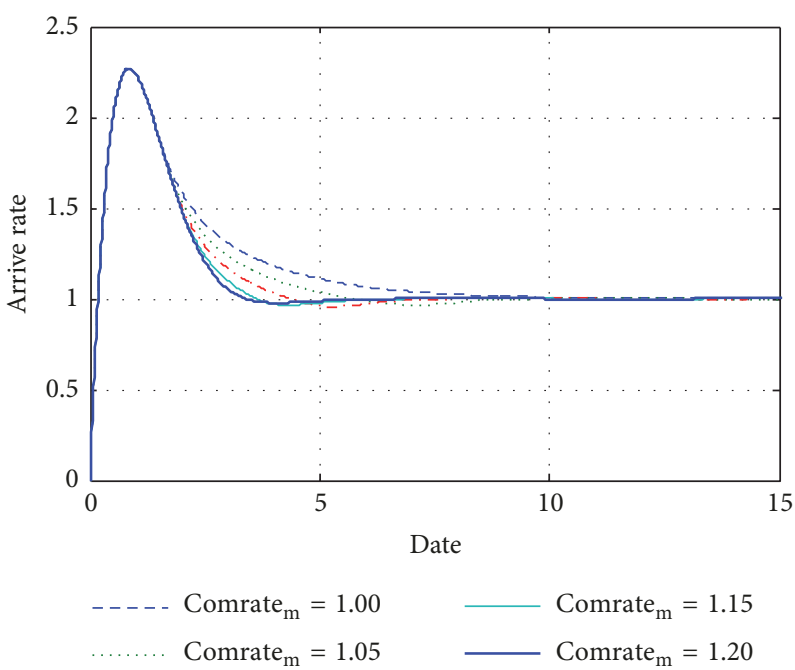

.....- Comrate $_{\mathrm{m}}=1.10$

(b) $\operatorname{arate}(t)$

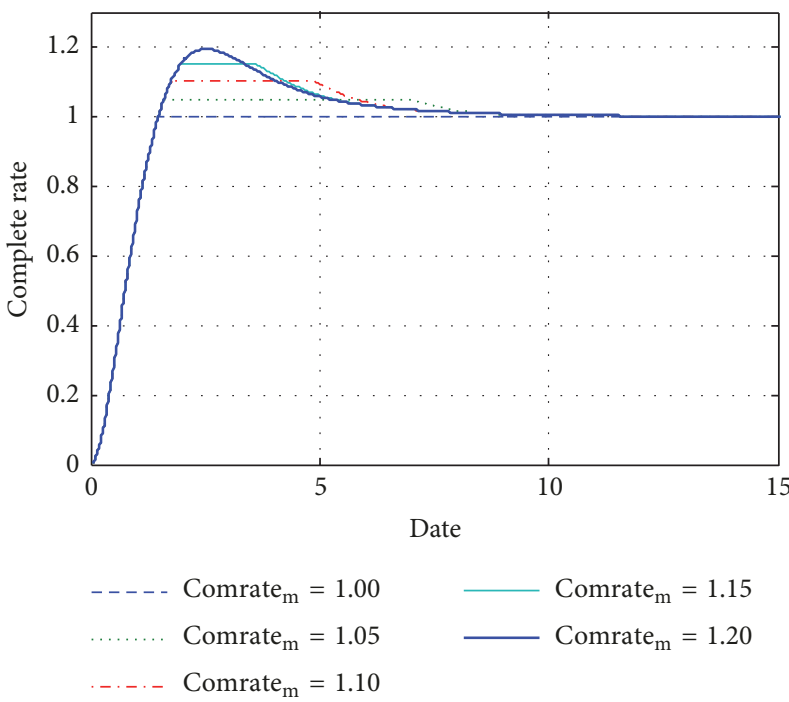

(c) comrate(t)

Figure 9: States and outputs in nonlinear HCS with different COMRATE . $_{\text {. }}$.

To investigate the influence of $C O M R A T E_{m}$ on ITAE, the proportion of $I T A E=\infty$ in nonlinear HCS with different COMRATE $_{m}$ is plotted in Figure 10. The observation of different COMRATE $E_{m}$ suggests the following: all values of $I T A E$ are infinite when COMRATE $E_{m} \leq 1$. When COM$R A T E_{m}=1 \sim 1.1$, the proportion of $I T A E=\infty$ clearly decreases. When COMRATE $E_{m}=1.1 \sim 1.2$, the proportion of ITAE $=\infty$ is close to 0 and decreases slowly. When $C O M R A T E_{m}=$ 1.2 , the proportion of $I T A E=\infty$ equals 0 , which is the same as that in the linear HCS. These observations show that the fluctuation of $u f r(t)$ could be alleviated if the nonlinear HCS is carefully designed, although it seems to be inevitable.

\section{Conclusion}

The emphasis of container port authorities and other players in the PSSC has shifted from traditional passive management to active response, highlighting the need to quantify the resilience of HCS for inevitable oscillations. This work builds and analyzes linear and nonlinear HCS models. Resilience for HCS in container ports is measured by ITAE of unsatisfied freight requirement. It provides a new perspective on PSSC partners to plan for HCS, where resilience could guide the selection of control parameters. HCSs in container ports are taken as example to analyze resilience, and it is found that Comrate $_{m}$ has significant influence on resilience for 


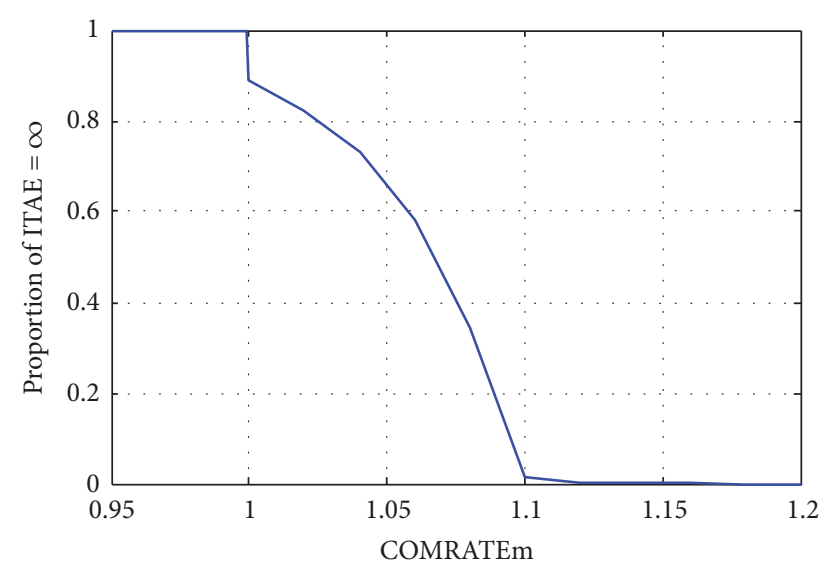

FIgURE 10: Proportion of ITAE $=\infty$ in nonlinear HCS with different COMRATE $_{m}$.

nonlinear model. These contributions serve as a starting point in the development of a quantitative resilience decision making framework for PSSC. Future work will consider the resilience and recovery strategies under stochastic freight requirements given the two HCSs.

\section{Data Availability}

The data used to support the findings of this study are included within the article.

\section{Conflicts of Interest}

The authors declare that they have no conflicts of interest.

\section{Acknowledgments}

This work is supported by the National Social Science Foundation project of China (No. 17CGL018). Here the authors would like to express their gratitude to it.

\section{References}

[1] J. J. Wang and M. C. Cheng, "From a hub port city to a global supply chain management center: a case study of Hong Kong," Journal of Transport Geography, vol. 18, no. 1, pp. 104-115, 2010.

[2] F. Wang, J. Huang, and Z. Liu, "Port management and operations: Emerging research topics and progress," Journal of Management Sciences in China, vol. 20, no. 05, pp. 111-126, 2017.

[3] B. Jiang, J. Li, and S. Shen, "Supply Chain Risk Assessment and Control of Port Enterprises: Qingdao port as case study," Asian Journal of Shipping and Logistics, vol. 34, no. 3, pp. 198-208, 2018.

[4] D. W. Song and P. M. Panayides, "Global supply chain and port/terminal: integration and competitiveness," in Proceedings of the International Conference on Logistics, Shipping and Port Management, Taiwan, March 2007.

[5] S. J. Pettit and A. K. C. Beresford, "Port development: From gateways to logistics hubs," Maritime Policy \& Management, vol. 36, no. 3, pp. 253-267, 2009.
[6] S.-H. Woo, S. J. Pettit, and A. K. C. Beresford, "An assessment of the integration of seaports into supply chains using a structural equation model," Supply Chain Management: An International Journal, vol. 18, no. 3, pp. 235-252, 2013.

[7] L. Hou and H. Geerlings, "Dynamics in sustainable port and hinterland operations: A conceptual framework and simulation of sustainability measures and their effectiveness, based on an application to the Port of Shanghai," Journal of Cleaner Production, vol. 135, pp. 449-456, 2016.

[8] K. L. Rødseth, P. B. Wangsness, and H. Schøyen, "How do economies of density in container handling operations affect ships' time and emissions in port? Evidence from Norwegian container terminals," Transportation Research Part D: Transport and Environment, vol. 59, pp. 385-399, 2018.

[9] J. Tongzon, Y. Chang, and S. Lee, "How supply chain oriented is the port sector?" International Journal of Production Economics, vol. 122, no. 1, pp. 21-34, 2009.

[10] C. Ta, A. V. Goodchild, and K. Pitera, "Structuring a definition of resilience for the freight transportation system," Transportation Research Record, no. 2097, pp. 19-25, 2009.

[11] A. H. Gharehgozli, J. Mileski, A. Adams, and W. von Zharen, "Evaluating a "wicked problem": A conceptual framework on seaport resiliency in the event of weather disruptions," Technological Forecasting \& Social Change, vol. 121, pp. 65-75, 2017.

[12] H. S. Loh and V. V. Thai, "Managing port-related supply chain disruptions (PSCDs): a management model and empirical evidence," Maritime Policy \& Management, vol. 43, no. 4, pp. 436-455, 2016.

[13] K. Zavitsas, T. Zis, and M. G. Bell, "The impact of flexible environmental policy on maritime supply chain resilience," Transport Policy, vol. 72, pp. 116-128, 2018.

[14] M. Saleh, R. Oliva, C. E. Kampmann, and P. I. Davidsen, “A comprehensive analytical approach for policy analysis of system dynamics models," European Journal of Operational Research, vol. 203, no. 3, pp. 673-683, 2010.

[15] B. Yang, X. Wang, Y. Zhang, Y. Xu, and W. Zhou, "Finitetime synchronization and synchronization dynamics analysis for two classes of markovian switching multiweighted complex networks from synchronization control rule viewpoint," Complexity, vol. 2019, Article ID 1921632, 17 pages, 2019.

[16] S. John, M. M. Naim, and D. R. Towill, "Dynamic analysis of a WIP compensated decision support system," International Journal of Manufacturing System Design, vol. 1, pp. 283-297, 1994.

[17] H. A. Gabbar, "Modeling approach for flexible production chain operation," IEEE Transactions on Systems, Man, and Cybernetics: Systems, vol. 38, no. 1, pp. 48-55, 2008.

[18] C. Li, R. Mo, Z. Chang, H. Yang, N. Wan, and D. Zhang, "Decision-making of feature operation chain considering processing requirements and manufacturing stability," The International Journal of Advanced Manufacturing Technology, vol. 87, no. 5-8, pp. 1-13, 2016.

[19] V. L. Spiegler and M. M. Naim, "Investigating sustained oscillations in nonlinear production and inventory control models," European Journal of Operational Research, vol. 261, no. 2, pp. 572-583, 2017.

[20] A. T. Almaktoom, "Stochastic reliability measurement and design optimization of an inventory management system," Complexity, vol. 2017, Article ID 1460163, 9 pages, 2017.

[21] J. Ma, L. Zhu, Y. Yuan, and S. Hou, "Study of the bullwhip effect in a multistage supply chain with callback structure considering 
two retailers," Complexity, vol. 2018, Article ID 3650148, 12 pages, 2018.

[22] R. Pant, K. Barker, J. E. Ramirez-Marquez, and C. M. Rocco, "Stochastic measures of resilience and their application to container terminals," Computers \& Industrial Engineering, vol. 70, no. 1, pp. 183-194, 2014.

[23] Y. Wang, S. W. Wallace, B. Shen, and T. Choi, "Service supply chain management: a review of operational models," European Journal of Operational Research, vol. 247, no. 3, pp. 685-698, 2015.

[24] D. R. Towill, "Dynamic analysis of an inventory and order based production control system," International Journal of Production Research, vol. 20, no. 6, pp. 671-687, 1982.

[25] L. Zhou, M. M. Naim, and S. M. Disney, "The impact of product returns and remanufacturing uncertainties on the dynamic performance of a multi-echelon closed-loop supply chain," International Journal of Production Economics, vol. 183, pp. 487502, 2017.

[26] V. L. M. Spiegler, M. M. Naim, and J. Wikner, "A control engineering approach to the assessment of supply chain resilience," International Journal of Production Research, vol. 50, no. 21, pp. 6162-6187, 2012. 


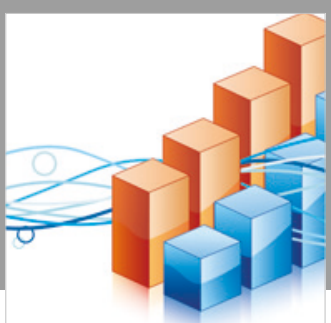

Advances in

Operations Research

\section{-n-m}
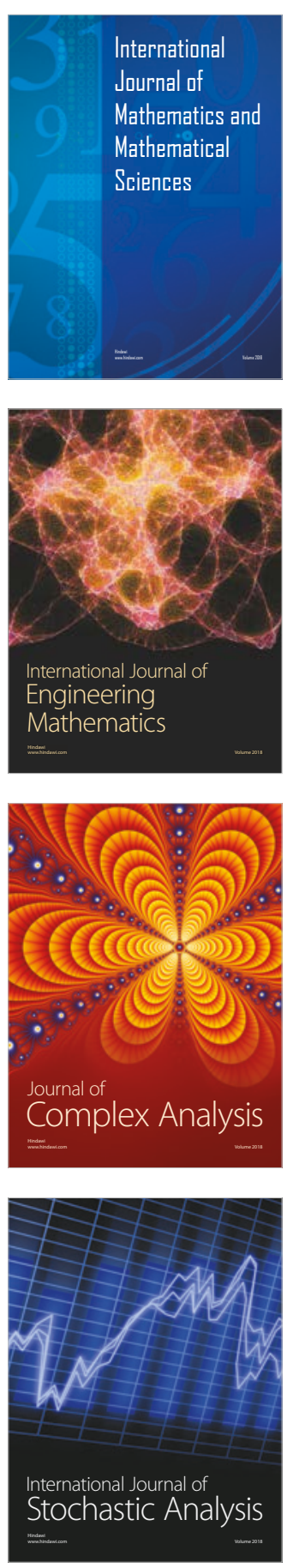
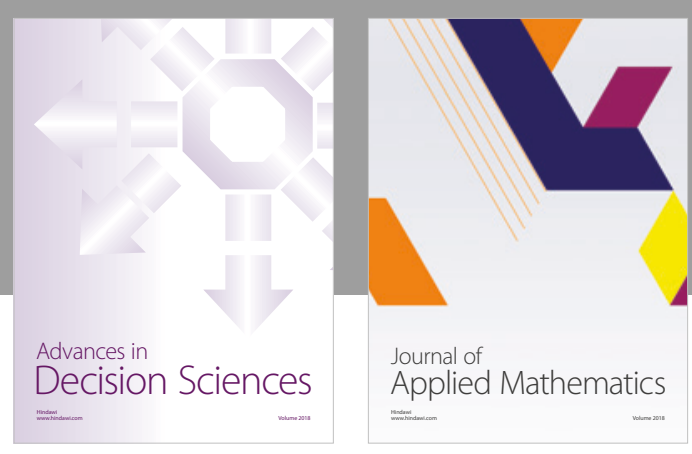

Journal of

Applied Mathematics
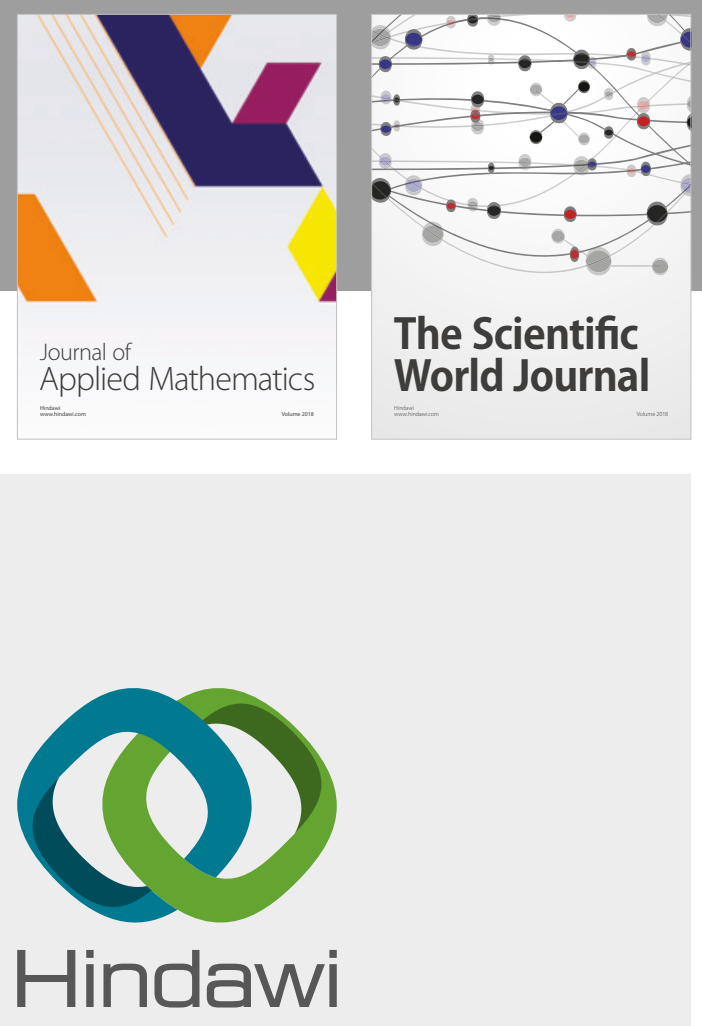

Submit your manuscripts at

www.hindawi.com

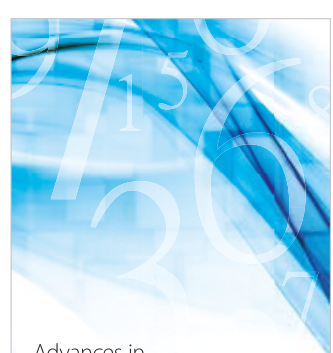

Advances in
Numerical Analysis


Mathematical Problems in Engineering

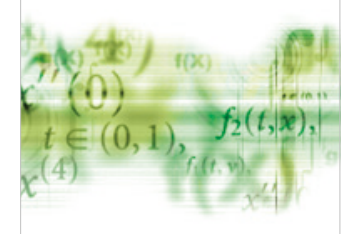

International Journal of

Differential Equations

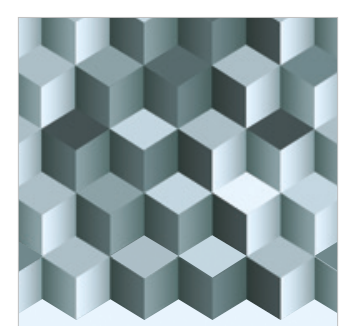

Journal of

Function Spaces
The Scientific

World Journal

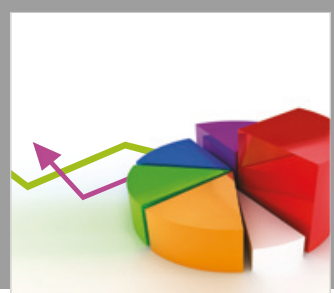

Journal of

Probability and Statistics
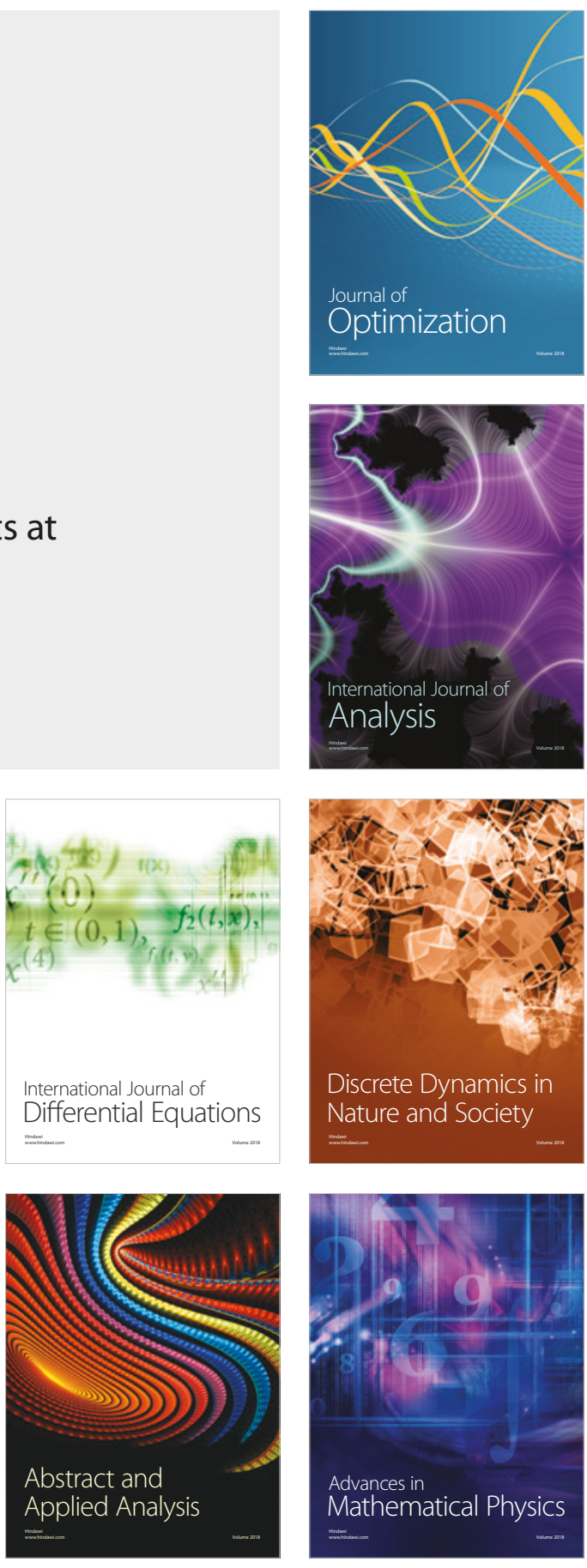